\title{
Sodium Intake and Blood Pressure in Patients with Chronic Kidney Disease: A Salty Relationship
}

\author{
Fabiana B. Nerbass ${ }^{a}$ b Viviane Calice-Silva ${ }^{a}$ b Roberto Pecoits-Filho ${ }^{a}$ \\ ${ }^{a}$ Department of Internal Medicine, School of Medicine, Pontificia Universidade Católica do Paraná, Curitiba, Brazil; \\ ${ }^{b}$ Division of Nephrology, Pro-Rim Foundation, Joinville, Brazil
}

\section{Keywords}

Chronic kidney disease - Sodium intake · Salt intake ·

Blood pressure

\begin{abstract}
Background: Hypertension affects almost all chronic kidney disease patients and is related to poor outcomes. Sodium intake is closely related to blood pressure (BP) levels in this population and decreasing its intake consistently improves the BP control particularly in short-term controlled trials. However, most patients struggle in following a controlled diet on sodium according to the guidelines recommendation due to several factors and barriers discussed in this article. Summary: This review article summarizes the current knowledge related to the associations between sodium consumption, BP, and the risk of cardiovascular disease and chronic kidney disease (CKD); it also provides recommendations of how to achieve sodium intake lowering. Key Messages: Evidences support the benefits in decreasing sodium intake on markers of cardiovascular and renal outcomes in CKD. Trials had shorter follow-up and to maintain long-term sodium intake control is a major challenge. Larger studies with longer follow-up looking at hard endpoints will be important to drive future recommendations.
\end{abstract}

(c) 2018 S. Karger AG, Basel

\section{KARGER}

(c) 2018 S. Karger AG, Basel

E-Mail karger@karger.com

www.karger.com/bpu

\section{Introduction}

Individuals with chronic kidney disease (CKD) generally have higher blood pressure (BP) levels than people with normal kidney function. These individuals are particularly sensitive to high salt intake, which may potentially have a greater impact on BP in patients with $\mathrm{CKD}$ than in those without CKD. This observation may be explained since by the reduction in the ability to excrete the salt load in the urine observed in patients with impaired kidney function. Salt reduction interventions offer the potential to lower BP in a simple, inexpensive, effective fashion, while also improving cardiovascular disease (CVD) and CKD progression risk. In this review article, we summarize the current knowledge related to the association between sodium consumption, $\mathrm{BP}$, and the risk of CVD and CKD, and provide recommendations of how to achieve a reduction in sodium intake.

\section{Sodium Consumption and Its Relationship with BP}

Sodium is an essential nutrient for the maintenance of plasma volume and plasma osmolality, and participates in several metabolic pathways essential to maintain life 
Fig. 1. Scheme of relationship between sodium intake, blood pressure (BP), kidney damage and cardiovascular disease. Excess sodium in chronic kidney disease $(\mathrm{CKD})$ is caused by decreased sodium excretion and high sodium intake (partially mediated by taste sensitivity). This increases cardiovascular risk not only via altered increments in extracellular volume and BP but also through the direct toxic effects of sodium in blood vessels (adapted from McMahon et al. [9]).

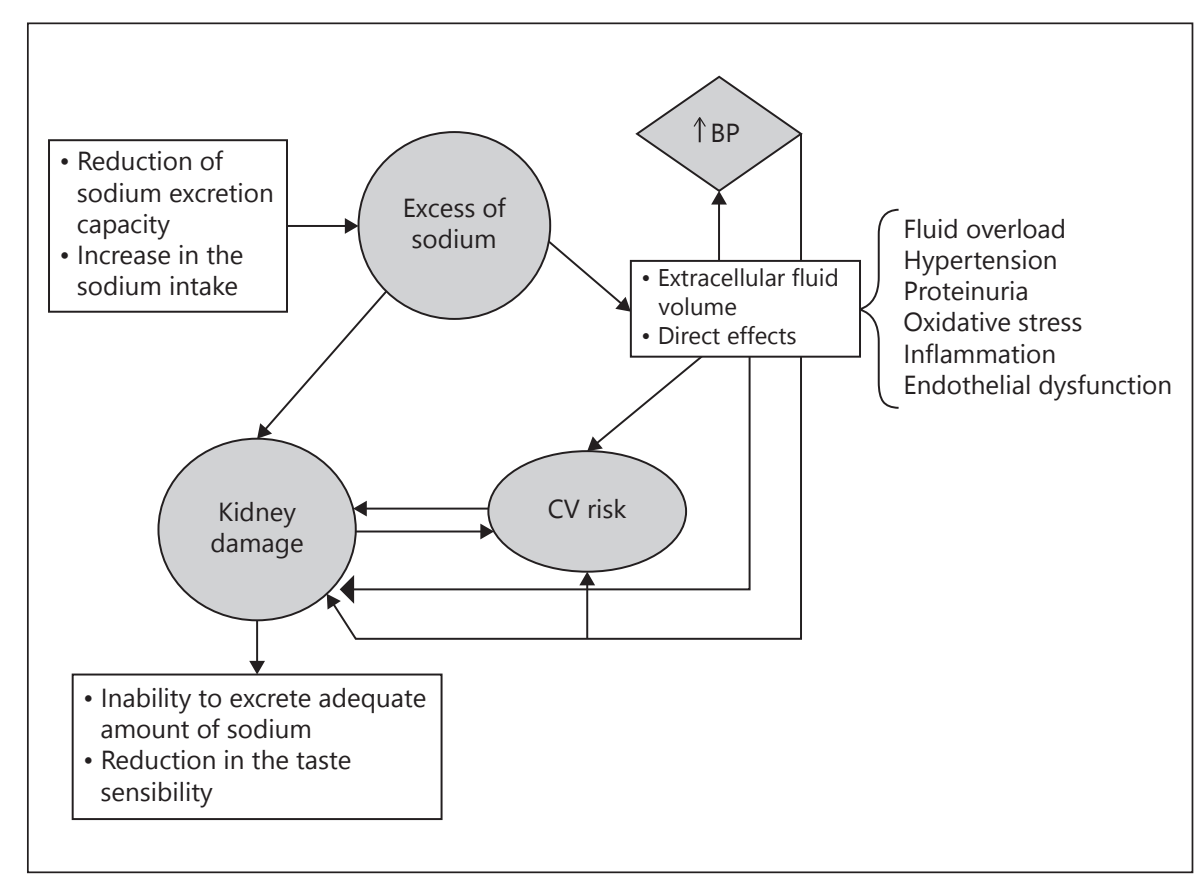

[1]. However, when consumed in excess, high sodium intake is an important risk factor for hypertension and is also associated with an increased risk of cardiovascular and kidney diseases [2, 3].

A systematic analysis of recently published, population-based studies from 90 countries concluded that in 2010 , one third of the world's adults had hypertension and that in one decade, the age-standardized prevalence of hypertension decreased by $2.6 \%$ in high-income countries, but increased by $7.7 \%$ in low and middleincome countries [4]. In fact, one of the important factors related to hypertension is high sodium consumption. The Global Burden of Diseases Nutrition and Chronic Diseases Expert Group concluded by means of a modeling study that $10 \%$ or 1.65 million deaths from cardiovascular causes that occurred in 2010 were attributed to sodium consumption above $2.0 \mathrm{~g} /$ day [5]. In fact, hypertension is known as the leading preventable risk factor for premature death and disability worldwide [6].

Therefore, based on solid scientific evidence, dietary guidelines recommend that sodium intake does not exceed $2-2.4 \mathrm{~g} /$ day $[1,7]$. However, the current intake is far higher in most populations around the world. Also, regarding 2010, the estimated mean sodium intake worldwide was $3.95 \mathrm{~g} /$ day and in 51 countries $(44.8 \%$ of the total adult population), it was over twice the recommended quantity [8].

$\mathrm{BP}$ and Sodium Intake in CKD

\section{Mechanisms Involved in the Relationship between Sodium Intake, Hypertension, Cardiovascular and Kidney Disease}

CVD is the leading cause of mortality in CKD population, with an increased risk of 5-10 times to die due to CVD than to progress to advanced stages of CKD. Several factors contribute to the development of CVD in this population, mostly related to previous comorbidities such as hypertension and diabetes mellitus. However, other risk factors are peculiar to CKD, namely, anemia, bone mineral disorders and (particularly relevant to this review) the inability to excrete the amount of sodium needed and consequent fluid overload [9]. Indeed, dietary sodium intake has been associated with numerous modifiable risk factors for CVD in CKD patients, including increased BP, volume overload, left ventricular hypertrophy, inflammation and endothelial damage [10-12]. Furthermore, markers of kidney damage, such as proteinuria, are also associated with high sodium intake [13, 14], and are the key risk factors for subsequent all-cause and cardiovascular mortality $[15,16]$. The main mechanisms involving sodium, BP, heart and kidney are presented in Figure 1.

Salt sensitivity, which is in part genetically determined, is one of the main determinants of BP response. Older age, obesity, diabetes mellitus, and particularly, renal malfunction can also modify the salt sensitivity process. 
A positive salt balance raises osmotic pressure, increases water intake and, as a consequence, rapidly causes hypervolemia $[12,17]$. Along the time, the increase in peripheral vascular resistance through the process of auto-regulation becomes the dominant determinant of BP [12]. Non-osmotic storage of salt has also been well documented and seems to interfere in the increased risk of cardiovascular and renal disease in the population $[12,18,19]$. CKD patients have a reduced ability to excrete high sodium intake, which interferes in the sodium balance increasing the susceptibility to the adverse effects of dietary sodium in their organism, some already described above (Fig. 1) $[19,20]$.

The effect of high dietary sodium intake in promoting fibrosis and other lesions is not restricted to the kidney, but it is also observed in the cardiovascular system [21]. The effects of angiotensin II and aldosterone are known to be amplified by a high salt intake. However, other mechanisms involved in the direct and BP-independent effects of high salt intake have been identified, such as increased transforming growth factor expression in kidney and aortic endothelial cells, impacting the cardiovascular and renal structure and function [22, 23].

Recently, measurements of atrial natriuretic peptide and brain natriuretic peptide have documented how frequently hypervolemia is present even in patients with advanced CKD patients who achieved dry weight. Controlling hypervolemia could achieve normotensive BP levels, without BP medications and also the regression of left ventricular hypertrophy is possible, thereby associating reduction in salt intake and control of hypervolemia in all stages of CKD [24, 25].

Considering the cardiovascular effects of sodium, it has been amply documented that not only ventricular hypertrophy [26] but also characteristics of the vasculature such as pulse pressure and vascular stiffness, as a consequence of some mechanisms already described here, are influenced by salt intake independent of BP or amplifying the response to high BP [27]. Elevated BP, fluid overload and the development of kidney disease also as a consequence of increased sodium balance will add even more damage to the heart in the long way increasing the mortality risk in CKD patients.

\section{Sodium Balance and BP in CKD}

Among CKD patients, the prevalence of hypertension is up to $92 \%$ [28-30] and inadequate sodium intake findings are not different from general population data. It has been demonstrated that $60-90 \%$ of these population consume sodium in excess [31-34], although literature had shown that efforts to reduce dietary sodium are particularly effective in reducing $\mathrm{BP}$ in this population (discussed further). This occurs because people with CKD are considered to represent a salt-sensitive population due to the inability to excrete a sodium load and diminished sodium-buffering capacity [25].

Although highly recommended, it is difficult to decrease and maintain adequate sodium intake due to many reasons. First, it seems that current health care does not provide patients with the necessary support to incorporate the sodium treatment guidelines into their daily life [35]. Second, even when support is available, sodium intake is often not evaluated in people with CKD in clinical practice due to the lack of a simple method [36]. The considered gold standard method by the World Health Organization - repeated 24-h urine collection - is subject to limitations such as high participant burden, the high cost of analysis, susceptibility to under- or over-collection of urine [37]. On the other hand, dietary assessment methods are considered easy to perform but are susceptible to errors related to memory lapses, reporting bias and interviewer skills $[38,39]$. The use of spot urine collection to estimate 24 -h sodium intake is simpler and has been explored recently, but up to now, no single formula has performed adequately when tested in different CKD populations $[33,40,41]$.

Third, there are several additional barriers that make it difficult for a patient's engagement to a low-sodium diet daily. Among Bangladeshis living in England, De BritoAshurst et al. [42] found that barriers to sodium restriction were deeply rooted dietary beliefs, attitudes and a culturally established taste for salt. Patients' lack of practical knowledge and intrinsic motivation, the maladaptive illness perceptions and refusal skills, the lack of social support and feedback regarding disease progression and sodium intake, and the availability of low-sodium foods were barriers to Dutch patients as revealed by an investigation with focus groups [43].

Recently, Meuleman et al. [35] studied 156 patients with CKD and identified that although they believed that limiting dietary sodium is beneficial, they still experience multiple difficulties. The domains classified as very important barriers were high sodium content in products, lack of sodium feedback, lack of goal setting and discussing strategies for sodium reduction, and not experiencing CKD-related symptoms. Furthermore, sodium reduction barrier domains were associated with age, level of education, number of comorbidities, per- 


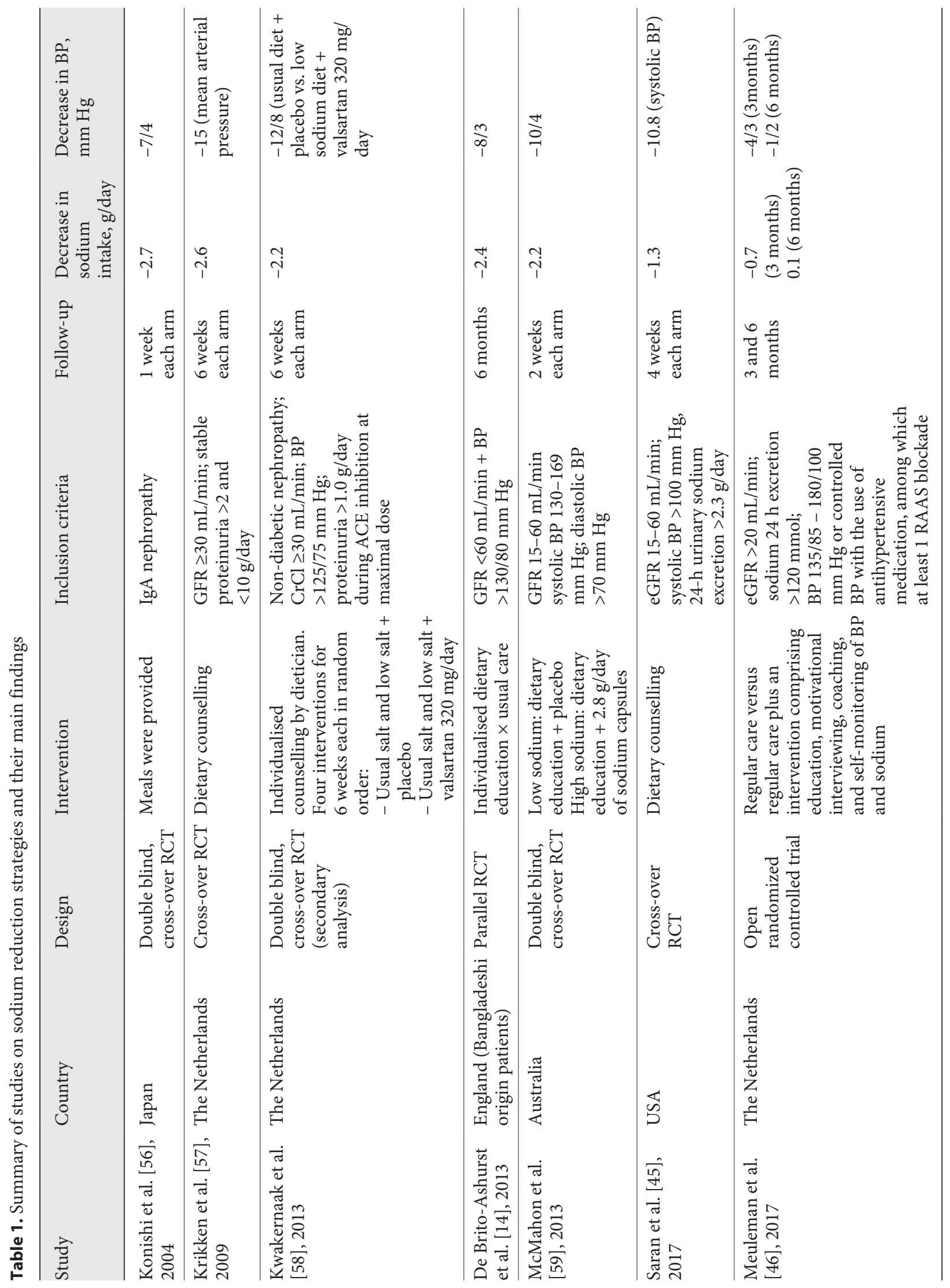


ceived autonomy support, depressive symptoms and self-efficacy.

These studies identified the following as a facilitator that helped one to adhere to a low-sodium diet: developing acceptable strategies for cooking with less salt without affecting palatability [42] (particularly important in countries where cooking salt is the main sodium source in habitual diet). Moreover, support strategies that target various sodium reduction barriers and strengthen beliefs regarding self-efficacy and autonomy support are extremely important [35]. Additionally, interventions to reduce sodium levels in processed foods, improve sodium-related product labels and increase consumer awareness are essential mainly in places where these products are the main source of sodium intake $[35,43]$.

\section{Impact of Sodium Intake Lowering and CV and Kidney Disease Risk}

Few studies analyzed the effects of salt restriction in CKD. In 2015, McMahon et al. [44] performed a systematic review including the results of 8 randomized controlled trials, with a total of 258 patients included, the average study duration being 6 weeks (summarized in Table 1). Five were performed in CKD patients with heterogeneous intervention methods, and most mostly including patients in early stages of CKD. Interestingly, reducing sodium intake was consistently associated with a decrease in $\mathrm{BP}$ by $8 / 3 \mathrm{~mm} \mathrm{Hg}$ mirrored by a drop in proteinuria ranging from 20 to $50 \%$ [44].

Two randomized controlled trials were published after the mentioned meta-analysis. In the cross-over study of Saran et al. [45], in which 58 patients were advised to reduce sodium intake for 4 weeks; a decrease of 1.3 g sodium resulted in a decrease of $10.8 \mathrm{~mm} \mathrm{Hg}$ in systolic BP, without impacting albuminuria. Meuleman et al. [46] compared patients in regular follow-up for over 6 months with those who received additional intervention with a focus on education, motivational interview, coaching and self-monitoring of BP and sodium consumption. They found modest improvement in outcomes after the first 3 months (sodium excretion, BP, and proteinuria), which decreased the follow-up time [46]. Thus, although effective in improving the control of risk factors for renal and cardiovascular outcomes in short periods, the clinical practice also shows that the adherence to a low-sodium diet for longer periods is a huge challenge for medical staff and patients.
Regarding the effect of lowering sodium intake in renal and cardiovascular outcomes, no clinical trial was performed. Available data on this relationship are from posthoc analysis and observational studies. The avoidance of high sodium intake increased the effect of renin-angiotensin-aldosterone system blockade in 2 post hoc analyses of clinical trials in these outcomes [47, 48]. The analysis of a large cohort of people with established CKD demonstrated the prospective association of high urinary sodium excretion with adverse outcomes, such as CVD incidence [49], CKD progression and all-cause mortality [50].

The KDIGO 2012 Clinical Practice Guideline for the Management of BP in Chronic Kidney Disease recommends lowering salt intake to $<90 \mathrm{mmol}(<2 \mathrm{~g})$ per day of sodium (corresponding to $5 \mathrm{~g}$ of sodium chloride), unless contraindicated (level of evidence: 1C) [51]. Specific strategies are important in the implementation of these recommendations. Sodium intake and dietary patterns vary enormously worldwide, and therefore, the strategies need to be based on the local reality. Some practical strategies developed in Brazil, South Africa, Japan and Italy are published; they can serve as examples of implementation at the local level taking into account local patterns and peculiarities [52-55].

\section{Summary and Conclusion}

There is good evidence supporting the positive effects in decreasing sodium intake on surrogate markers of cardiovascular events (BP) and progression of kidney disease (albuminuria) in CKD patients. Moreover, most of the trials available in the area have a relatively shorter followup, and the long-term sustainability of a low-sodium diet is a major challenge, since it involves not only patient's self-motivation but also tailored multidisciplinary approach, family involvement and government actions. Larger studies with longer follow-up periods looking at hard endpoints will be important to drive future recommendations related to sodium intake, and particularly efficient strategies for implementation of this low-cost measure with potential impact in kidney and cardiovascular disease are to be developed.

\section{Disclosure Statement}

F.B.N. and V.C.-S. have no disclosure. R.P.-F. receives Speake fees and research honoraria from Janssen, AstraZeneca, Novartis, Akebia, Baxter, and Fresenius Medical Care. 


\section{References}

1 Institute of Medicine: Dietary Reference Intakes for Water, Potassium, Sodium, Chloride, and Sulfate. National Academies Press, Washington, 2005, p 640.

2 Zhao D, Qi Y, Zheng Z, Wang Y, Zhang XY, Li HJ, et al: Dietary factors associated with hypertension. Nat Rev Cardiol 2011;8:456-465.

3 He FJ, MacGregor GA: Reducing population salt intake worldwide: from evidence to implementation. Prog Cardiovasc Dis 2010;52: 363-382.

4 Mills KT, Bundy JD, Kelly TN, Reed JE, Kearney PM, Reynolds K, et al: Global disparities of hypertension prevalence and control: a systematic analysis of population-based studies from 90 countries. Circulation 2016;134:441450.

5 Mozaffarian D, Fahimi S, Singh GM, Micha R, Khatibzadeh S, Engell RE, et al: Global sodium consumption and death from cardiovascular causes. N Engl J Med 2014;371:624-634.

6 O'Brien E, Pickering T, Asmar R, Myers M, Parati G, Staessen J, et al: Working Group on Blood Pressure Monitoring of the European Society of Hypertension International Protocol for validation of blood pressure measuring devices in adults. Blood Press Monit 2002;7: 3-17.

7 World Health Organization: WHO | Sodium Intake for Adults and Children. Geneva, World Health Organization, 2012, p 56.

8 Powles J, Fahimi S, Micha R, Khatibzadeh S, Shi P, Ezzati M, et al: Global, regional and national sodium intakes in 1990 and 2010: a systematic analysis of $24 \mathrm{~h}$ urinary sodium excretion and dietary surveys worldwide. BMJ Open 2013;3:e003733.

9 McMahon EJ, Bauer JD, Hawley CM, Isbel NM, Stowasser M, Johnson DW, et al: The effect of lowering salt intake on ambulatory blood pressure to reduce cardiovascular risk in chronic kidney disease (LowSALT CKD study): protocol of a randomized trial. BMC Nephrol 2012;13:137.

10 Essig M, Escoubet B, de Zuttere D, Blanchet F, Arnoult F, Dupuis E, et al: Cardiovascular remodelling and extracellular fluid excess in early stages of chronic kidney disease. Nephrol Dial Transplant 2008;23:239-248.

11 Sacks FM, Svetkey LP, Vollmer WM, Appel LJ, Bray GA, Harsha D, et al: Effects on blood pressure of reduced dietary sodium and the Dietary Approaches to Stop Hypertension (DASH) diet. DASH-Sodium Collaborative Research Group. N Engl J Med 2001;344:3-10.

12 Ritz E, Dikow R, Morath C, Schwenger V: Salt - a potential 'uremic toxin'? Blood Purif 2006; 24:63-66.

13 Verhave JC, Hillege HL, Burgerhof JG, Janssen WM, Gansevoort RT, Navis GJ, et al: Sodium intake affects urinary albumin excretion especially in overweight subjects. J Intern Med 2004;256:324-330.

14 De Brito-Ashurst I, Perry L, Sanders TA, Thomas JE, Dobbie H, Varagunam M, et al:
The role of salt intake and salt sensitivity in the management of hypertension in South Asian people with chronic kidney disease: a randomised controlled trial. Heart 2013;99: 1256-1260.

15 Anavekar NS, Gans DJ, Berl T, Rohde RD, Cooper W, Bhaumik A, et al: Predictors of cardiovascular events in patients with type 2 diabetic nephropathy and hypertension: a case for albuminuria. Kidney Int Suppl 2004; 66:S50-S55.

16 Borch-Johnsen K, Kreiner S: Proteinuria: value as predictor of cardiovascular mortality in insulin dependent diabetes mellitus. Br Med J (Clin Res Ed) 1987;294:1651-1654.

17 Titze J, Shakibaei M, Schafflhuber M, Schulze-Tanzil G, Porst M, Schwind KH, et al: Glycosaminoglycan polymerization may enable osmotically inactive $\mathrm{Na}+$ storage in the skin. Am J Physiol Heart Circ Physiol 2004; 287:H203-H208.

18 Guyton AC: Dominant role of the kidneys and accessory role of whole-body autoregulation in the pathogenesis of hypertension. Am J Hypertens 1989;2:575-585.

19 Kimura G, Dohi Y, Fukuda M: Salt sensitivity and circadian rhythm of blood pressure: the keys to connect CKD with cardiovasucular events. Hypertens Res 2010;33:515-520.

20 Koomans HA, Roos JC, Boer P, Geyskes GG, Mees EJ: Salt sensitivity of blood pressure in chronic renal failure. Evidence for renal control of body fluid distribution in man. Hypertension 1982;4:190-197.

21 Yu HC, Burrell LM, Black MJ, Wu LL, Dilley RJ, Cooper ME, et al: Salt induces myocardial and renal fibrosis in normotensive and hypertensive rats. Circulation 1998;98:2621-2628.

22 Rocha R, Funder JW: The pathophysiology of aldosterone in the cardiovascular system. Ann N Y Acad Sci 2002;970:89-100.

23 Joffe HV, Adler GK: Effect of aldosterone and mineralocorticoid receptor blockade on vascular inflammation. Heart Fail Rev 2005;10: 31-37.

24 Ozkahya M, Ok E, Cirit M, Aydin S, Akçiçek F, Başçi A, et al: Regression of left ventricular hypertrophy in haemodialysis patients by ultrafiltration and reduced salt intake without antihypertensive drugs. Nephrol Dial Transplant 1998;13:1489-1493.

25 Ozkahya M, Toz H, Qzerkan F, Duman S, Ok E, Basci A, et al: Impact of volume control on left ventricular hypertrophy in dialysis patients. J Nephrol 2002;15:655-660.

26 Messerli FH, Schmieder RE, Weir MR: Salt. A perpetrator of hypertensive target organ disease? Arch Intern Med 1997;157:2449-2452.

27 du Cailar G, Mimran A, Fesler P, Ribstein J, Blacher J, Safar ME: Dietary sodium and pulse pressure in normotensive and essential hypertensive subjects. J Hypertens 2004;22:697703.

28 Fraser SD, Roderick PJ, McIntyre NJ, Harris S, McIntyre CW, Fluck RJ, et al: Suboptimal blood pressure control in chronic kidney disease stage 3: baseline data from a cohort study in primary care. BMC Fam Pract 2013; 14:88.

29 Kalaitzidis R, Li S, Wang C, Chen SC, McCullough PA, Bakris GL: Hypertension in early-stage kidney disease: an update from the Kidney Early Evaluation Program (KEEP). Am J Kidney Dis 2009;53(4 suppl 4):S22-S31.

30 Kuznik A, Mardekian J, Tarasenko L: Evaluation of cardiovascular disease burden and therapeutic goal attainment in US adults with chronic kidney disease: an analysis of national health and nutritional examination survey data, 2001-2010. BMC Nephrol 2013;14:132.

31 Ogura M, Kimura A, Takane K, Nakao M, Hamaguchi A, Terawaki H, et al: Estimation of salt intake from spot urine samples in patients with chronic kidney disease. BMC Nephrol 2012;13:36.

32 Nerbass FB, Pecoits-Filho R, McIntyre NJ, McIntyre CW, Willingham FC, Taal MW: Demographic associations of high estimated sodium intake and frequency of consumption of high-sodium foods in people with chronic kidney disease stage 3 in England. J Ren Nutr 2014;24:236-242.

33 Nerbass FB, Hallvass AE, Taal MW, PecoitsFilho R: Formula to detect high sodium excretion from spot urine in chronic kidney disease patients. J Bras Nefrol 2017;39:23-28.

$34 \mathrm{Yu} \mathrm{W,} \mathrm{Luying} \mathrm{S,} \mathrm{Haiyan} \mathrm{W,} \mathrm{Xiaomei} \mathrm{L:} \mathrm{Im-}$ portance and benefits of dietary sodium restriction in the management of chronic kidney disease patients: experience from a single Chinese center. Int Urol Nephrol 2012;44: 549-556.

35 Meuleman Y, Hoekstra T, Dekker FW, van der Boog PJ, van Dijk S; ESMO Study Group: Perceived sodium reduction barriers among patients with chronic kidney disease: which barriers are important and which patients experience barriers? Int J Behav Med 2017, Epub ahead of print.

36 Boudville N, Ward S, Benaroia M, House AA: Increased sodium intake correlates with greater use of antihypertensive agents by subjects with chronic kidney disease. Am J Hypertens 2005;18:1300-1305.

37 Elliott P, Brown I: Sodium Intakes Around the World. Geneva, World Health Organization, 2007.

38 Jain M, Howe GR, Rohan T: Dietary assessment in epidemiology: comparison on food frequency and a diet history questionnaire with a 7-day food record. Am J Epidemiol 1996;143:953-960.

39 Bingham SA: Limitations of the various methods for collecting dietary intake data. Ann Nutr Metab 1991;35:117-127.

40 Nerbass FB, Pecoits-Filho R, McIntyre NJ, McIntyre CW, Taal MW: Development of a formula for estimation of sodium intake from spot urine in people with chronic kidney disease. Nephron Clin Pract 2014;128:61-66. 
41 Dougher CE, Rifkin DE, Anderson CA, Smits G, Persky MS, Block GA, et al: Spot urine sodium measurements do not accurately estimate dietary sodium intake in chronic kidney disease. Am J Clin Nutr 2016;104:298305.

42 de Brito-Ashurst I, Perry L, Sanders TA, Thomas JE, Yaqoob MM, Dobbie H: Barriers and facilitators of dietary sodium restriction amongst Bangladeshi chronic kidney disease patients. J Hum Nutr Diet 2011;24: 86-95.

43 Meuleman Y, ten Brinke L, Kwakernaak AJ, Vogt L, Rotmans JI, Bos WJ, et al: Perceived barriers and support strategies for reducing sodium intake in patients with chronic kidney disease: a Qualitative study. Int J Behav Med 2015;22:530-539.

44 McMahon EJ, Campbell KL, Bauer JD, Mudge DW: Altered dietary salt intake for people with chronic kidney disease. Cochrane database Syst Rev 2015;2:CD010070.

45 Saran R, Padilla RL, Gillespie BW, Heung M, Hummel SL, Derebail VK, et al: A randomized crossover trial of dietary sodium restriction in stage 3-4 CKD. Clin J Am Soc Nephrol 2017;12:399-407.

46 Meuleman Y, Hoekstra T, Dekker FW, Navis G, Vogt L, van der Boog PJM, et al: Sodium restriction in patients with CKD: a randomized controlled trial of self-management support. Am J Kidney Dis 2017;69: 576-586.
47 Vegter S, Perna A, Postma MJ, Navis G, Remuzzi G, Ruggenenti P: Sodium intake, ACE inhibition, and progression to ESRD. J Am Soc Nephrol 2012;23:165-173.

48 Lambers Heerspink HJ, Holtkamp FA, Parving HH, Navis GJ, Lewis JB, Ritz E, et al: Moderation of dietary sodium potentiates the renal and cardiovascular protective effects of angiotensin receptor blockers. Kidney Int 2012;82:330-337.

49 Mills KT, Chen J, Yang W, Appel LJ, Kusek JW, Alper A, et al: Sodium excretion and the risk of cardiovascular disease in patients with chronic kidney disease. JAMA 2016;315: 2200-2210.

50 He J, Mills KT, Appel LJ, Yang W, Chen J, Lee BT, et al: Urinary sodium and potassium excretion and CKD progression. J Am Soc Nephrol 2016;27:1202-1212.

51 National Kidney Foundation: KDIGO clinical practice guideline for the management of blood pressure in chronic kidney disease. Kidney Int 2012;2(suppl):337-414.

52 Cuppari L, Nerbass FB, Avesani CM, Kamimura MA: A practical approach to dietary interventions for nondialysis-dependent CKD patients: the experience of a reference nephrology center in Brazil. BMC Nephrol 2016; 17:85.

53 Ameh OI, Cilliers L, Okpechi IG: A practical approach to the nutritional management of chronic kidney disease patients in Cape Town, South Africa. BMC Nephrol 2016;17:68.
54 Iseki K, Yamagata K: A practical approach of salt and protein restriction for CKD patients in Japan. BMC Nephrol 2016;17:87.

55 D'Alessandro C, Piccoli GB, Calella P, Brunori G, Pasticci F, Egidi MF, et al: "Dietaly": practical issues for the nutritional management of CKD patients in Italy. BMC Nephrol 2016;17:102.

56 Konishi Y, Morikawa T, Yasu T, Teramoto K, Okada N, Yoshioka K, et al: Blunted response of the Renin-Angiotensin system and nitric oxide synthesis related to sodium sensitivity in immunoglobulin a nephropathy. Hypertens Res 2004;27:7-13.

57 Krikken JA, Waanders F, Dallinga-Thie GM, Dikkeschei LD, Vogt L, Navis GJ, et al: Antiproteinuric therapy decreases LDL-cholesterol as well as HDL-cholesterol in non-diabetic proteinuric patients: relationships with cholesteryl ester transfer protein mass and adiponectin. Expert Opin Ther Targets 2009;13: 497-504.

58 Kwakernaak AJ, Lambert G, Slagman MC, Waanders F, Laverman GD, Petrides F, et al: Proprotein convertase subtilisin-kexin type 9 is elevated in proteinuric subjects: relationship with lipoprotein response to antiproteinuric treatment. Atherosclerosis 2013;226: 459-465.

59 McMahon EJ, Bauer JD, Hawley CM, Isbel NM, Stowasser M, Johnson DW, et al: A randomized trial of dietary sodium restriction in CKD. J Am Soc Nephrol 2013;24:2096-2103. 